\title{
Online Participation in Higher Education Decision-Making
}

\author{
A mixed-methods study of the MyUniversity EU project
}

\author{
Samuel Bohman, Henrik Hansson*, Pooyeh Mobini** \\ Department of Computer and Systems Sciences, Stockholm University, Nodhuset, Borgarfjordsgatan 12, Kista, Sweden, \\ samboh@dsv.su.se, *henrik.hansson@dsv.su.se, **pooyeh@dsv.su.se, Tel: +468162000
}

\begin{abstract}
This article considers online participation in higher education decision-making using the MyUniversity EU project as a case study. MyUniversity was a pilot designed to provide European universities with a web-based system to empower and involve students and other members of the academic community in the Bologna Process. Thirteen universities in Spain, Slovakia, Bulgaria, and Lithuania participated in trials. The study uses data collection methods from across the quantitative and qualitative spectrum: web analytics, online surveys, key performance indicators, interviews, focus groups, participant observation, document studies, and usability evaluations. The results are represented by 10 themes: project design, participation, functionality and usability, impact on decision-making, privacy and trust, institutional resistance, motivational factors, the political, economic, and sociocultural context, language barriers, and moderation and framing. The article ends with a discussion based on the results, including recommendations for future research.
\end{abstract}

Keywords: Bologna Process, decision-making, e-democracy, e-participation, empowerment, higher education

Acknowledgment: This research was partially supported by the European Commission under the ICT Policy Support Programme (project no. 256216). The opinions expressed here do not necessarily reflect the policy of the European Commission, however.

M yUniversity was a pilot project designed to provide European universities with a web-based system to empower and involve students and other members of the academic community in the Bologna Process by means of social networking, new intermediation models, and Web 2.0 technology. Eight universities in Europe participated in trials: University King Juan Carlos (URJC) and the University of León (UL) in Spain, Slovak University of Agriculture in Nitra (SPUVN), Slovak University of Technology in Bratislava (STU), and the University of Prešov in Prešov (PU) in Slovakia, the International Business School (IBS) and the University of National and World Economy (UNWE) in Bulgaria, and Vilnius University (VU) in Lithuania. Five Catalan universities coordinated by the Center for Scientific and Academic Services of Catalonia (CESCA) also participated: the Autonomous University of Barcelona (UAB), the University of Barcelona (UB), the Polytechnic University of Catalonia (UPC), the University of Girona (UdG), and the University of Lleida (UdL).

Each trial was provided with an e-participation portal with tools which allowed its users to interact locally and across borders through an EU-level super-portal. MyUniversity was based on two earlier e-participation projects, Gov2DemOSS and Demos@Work, both co-financed by the European Commission. The system was an adaptation of an open source content management system (Joomla) for publishing web content and included standard features such as a discussion forum, quick poll, newsletter, calendar, profile page, and search. It also included a petition tool, a tool for sending letters to officials, a translation plugin built on Google Translate, Facebook and Twitter integration, and a tool for handling decision-making processes. A proprietary Internet voting solution called Pnyx from the Spanish company Scytl was also included on the MyUniversity platform. 
At the end of the project, existing trial universities had to pay an annual fee for using the system including maintenance and technical support. The total duration of the project was 33 months and it ran from October 2010 until June 2013. The aim of this article is to study online participation in higher education decision-making using the MyUniversity project as a case, derive lessons learned, and provide recommendations for future research.

\section{Theoretical Framework}

\subsection{Challenges and Barriers}

A number of literature and project reviews have been conducted to characterize and consolidate the e-participation field (Chrissafis \& Rohen, 2010; Freschi, Medaglia, \& Nørbjerg, 2009; Koussouris, Charalabidis, \& Askounis, 2011; Macintosh, Coleman, \& Schneeberger, 2009; Macintosh, 2004, 2008; Medaglia, 2007, 2011, 2012; Panopoulou, Tambouris, \& Tarabanis, 2009; Prieto-Martín, de Marcos, \& Martínez, 2012; Sæbø, Rose, \& Skiftenes Flak, 2008; Sanford \& Rose, 2007; Susha \& Grönlund, 2012). The reviews describe a rapidly growing field with research published on a range of topics, including e-participation actors, activities, contextual factors, effects, evaluation, theories and research methods (Sæbø et al., 2008). The typical background of many e-participation pilots is a European democracy in decline, characterized by falling voter turnouts and lack of trust in governments and politicians. In this context, the potential of information and communications technology (ICT) has been increasingly and uncritically promoted as having great potential to improve openness, to foster transparency, and to re-engage citizens with democratic processes. However, the evidence of the benefits of e-participation is poor, as is that for more traditional forms of participation (Macintosh et al., 2009). A recent critical review of EUfunded e-participation suggests that projects since the early 2000s have not been as successful as anticipated despite significant investments (Prieto-Martín et al., 2012). It describes the typical eparticipation pilot system as not user-friendly, error prone, and built on outdated general-purpose tools that generated low participation at very high cost, around 550 euros per user contribution.

Many challenges and barriers have been identified as hindering the advancement of eparticipation. Sanford and Rose (2007) identified four central challenges. First, there is a need to understand the relationship between technology and participation better, in particular the effects of technology on participation. The study of spontaneous bottom-up participation such as blogging, grassroots activism, social movements, and political campaigning should receive more attention, according to the authors. Second, the strategic challenge deals with the question of which form of democracy and participation is desirable. The third challenge concerns the sociotechnical design of e-participation systems addressing problems of engagement, trust, privacy, and other aspects. Finally, Sanford and Rose underline the need for evaluation of projects for better understanding of their effects, particularly for continuous learning, adjustment of research strategies and design efforts.

Macintosh et al. (2009) identified six thematic challenges, barriers and needs associated with eparticipation. First, they argue that the breadth of the field has resulted in fragmented research lacking consistent terminology, definitions, and shared concepts. Second, research design needs stronger emphasis on comprehensive and interdisciplinary strategies and methods along with greater critical reflection. Mixed-method research designs are suggested to counterbalance the deficiencies and overconfidence of individual methods. Furthermore, immature research designs have consistently undervalued the importance of spontaneous, bottom-up participation on the Internet, driven by citizens, voluntary organizations, and pressure groups. Third, e-participation needs to go beyond deterministic claims that new ICT is bound to have (positive) consequences for democracy. Instead, it should embrace the complexities of political power relations and sociocultural dynamics that are inherent in all decision-making. The field needs to take into account issues such as expectations, skills, contexts, and purposes, connecting with organizational work practices and everyday life. There is also a need to include mobile devices and social networks in the design of participation technologies. 
A related unchallenged assumption concerns direct democracy as the ideal form of democratic participation and the conclusion that increased use of technology will lead to increases in participation and consequently better democracy. Democracy models that are commonly used in eparticipation are often influenced by narratives of linear progress inherited from the e-government literature (Chadwick, 2011). Typically, they convey a progression from good (e.g. providing information) to better (e.g. consultation) to best (e.g. delegation of power), lacking the dimensions of conflict characteristic of all types of decision-making (Grönlund, 2009).

Fourth, a major challenge for e-participation concerns institutional resistance and the distribution of decision-making power. Without serious commitment and support from decision-makers, eparticipation initiatives will rarely achieve any greater impact. Power can, and often does, stand in the way of realizing e-participation practice. The goal is to find a balance between problem-solving and power-sharing which benefits both sides. Fifth, equity and inclusion is a challenge in all forms of participation, offline and online, especially in relation to multi-cultural and multi-ethnic minority groups. Online participation typically reinforces existing power relations, democratic divides and deficits, as it tends to favor the technological and political elite. Important "divides" include the civic divide (the resourceful versus the non-resourceful), the digital divide (unequal access to the Internet) and the language divide (English speakers versus non-English speakers, presuming the dominance of English in international political discourse). Sixth, e-participation research suffers from being seriously under-theorized, which has led to superficial studies overlooking actor motives, interests, values, and outcomes. It is also important for researchers to maintain a critical distance from e-participation practice to enable them to challenge the assumptions upon which eparticipation projects are based and expose potential conflicting interests, including claims made by technology vendors, project managers, officials, and other beneficiaries.

\subsection{Guidelines and Recommendations}

In short, the e-participation field does not know what works, when, and why (Aicholzer et al., 2008). However, there are a number of general guidelines and recommendations which are seen as good practice (Millard et al., 2009). The specific guidelines include recommendations such as:

- focus on real needs at the outset;

- build citizen participation from the bottom;

- ensure high-level backing;

- online participation must be extremely engaging to maximize participation;

- combine online and offline channels;

- ensure content quality and presentation;

- match technology and channels to participant needs;

- follow ICT advancements, experiment and adopt new trends;

- apply principles of good e-participation design;

- build on-going evaluation into all initiatives.

All the above guidelines and recommendations are based on results, benefits, and lessons learned from a large number of e-participation cases across Europe launched by the EU, nongovernmental organizations, and civil society organizations.

\subsection{Evaluation Frameworks}

In combination with the research results and good practice guidelines outlined above, this study draws on evaluation frameworks suggested in the literature in order to provide theoretically sound conclusions. Two frameworks have been used in particular: DEMO-net's layered evaluation model (Aicholzer et al., 2008), and the e-participation analytical framework (Smith, Macintosh, \& Millard, 
2009). These two frameworks are briefly described below and to some extent adjusted for the purposes of this study.

DEMO-net's layered evaluation model (LEM) distinguishes between three main purposes of evaluation: audit, management, and learning. This study is primarily concerned with learning since the e-participation field is in its embryonic phase. LEM integrates three overlapping perspectives on e-participation: the project perspective, the sociotechnical perspective, and the democratic perspective. The project perspective, as the name implies, focuses on evaluating project outcomes against predefined objectives. In the MyUniversity project, the key performance indicators (KPIs) which comprise various quantitative measures served a similar purpose. The sociotechnical perspective looks at usage, social acceptability, usefulness, usability, and satisfaction with tested technologies and tools. The democratic perspective involves investigating to what extent the eparticipation initiative affects decision-making in relation to underlying principles and values of democracy. In this study, it involved investigating the engagement of key stakeholder groups and concrete decision-making outcomes in relation to the democratic values of deliberation, respect, transparency, trust, and inclusiveness.

The e-participation analytical framework (EAF) of the European e-participation study has an open system analytic perspective and distinguishes between three different levels of goals for eparticipation: project outputs, decision-making outcomes, and societal impacts. Project outputs are lower-level goals specific to the project and are usually short-term and measurable, for example, KPIs. Decision-making outcomes are mid-level goals which affect a wider group of stakeholders and beneficiaries in the political sphere. Societal impacts are high-level policy goals and governance ambitions of EU institutions such as civic trust, empowerment, and innovation. Like all system analytic models, EAF employs the idea of system intervention. EAF specifies actions which are necessary in order to embed the e-participation project successfully in its political, economic, sociocultural, and institutional environment. It means asking the question: how well does the project fit into its environment, and how well do interventions lead to an embedding process? EAF distinguishes between internal and external factors acting as drivers or barriers to embedding the project in its specific environment. Three main possible transformation failures are suggested:

- the intervention logic is faulty, i.e., not plausible, realistic, or internally consistent;

- the intervention logic is misaligned with external factors;

- an unanticipated, or wrongly anticipated, barrier arises.

External, contextual factors include but are not limited to (relevant examples in parentheses):

- regime type (public university);

- decision-making practice and culture (no established participation activities);

- working practices and culture (low levels of trust);

- legal environment (higher education regulations and laws);

- policy environment (Bologna Process);

- level of autonomy (level of self-government of universities);

- existing technologies and tools (FirstClass, Mondo, etc.);

- socioeconomic environment (economic crisis, financial cuts, social unrest);

- sociocultural environment (language barriers, democratic traditions).

EAF acknowledges the existence of power relations between the dominant governance regime and those who are governed, the supposedly active citizens. This means that e-participation also takes place away from official governmental platforms to escape these power relations and create a more authentic and autonomous deliberative space. Finally, EAF includes consideration of eparticipation in relation to the standard policy lifecycle, a number of possible low-level outputs, mid- 
level outcomes, high-level impacts, intervention logics, and a list of suggested "raw materials" (technologies, human resources, finance, time, etc.). However, these dimensions are less important for the purposes of this study and are not discussed further.

\section{Methods}

The mixing or integrating of quantitative and qualitative methods in one single study is generally considered good practice in information systems and computing research since it provides multiple perspectives on a research problem and enhances its validity (Oates, 2006). In this context, the term quantitative refers to variables that can be measured and expressed numerically. The term qualitative implies interpretation of non-numerical data. In the field of evaluation research, the argument for mixed methods has acquired particularly strong support (Tashakkori \& Teddlie, 2003). As a quintessentially applied field concerned with specific policies and practices rather than general truths, e-participation requires pragmatism. This involves the use of both quantitative and qualitative research methods to allow for breadth, depth, richness, and nuance in data and understanding. Consequently, the rationale for using mixed methods in e-participation research is strong, given its multifaceted, multi-stakeholder nature (Macintosh \& Whyte, 2006).

In this study, there were three specific reasons for integrating quantitative and qualitative methods, namely: (1) triangulation, in order to achieve greater validity by counteracting inherent method bias, (2) complementarity, i.e., elaboration, illustration, explanation, and to provide contextual understanding, and (3) method development, i.e., one data set provides information for subsequent data collection (Bryman, 2006; Greene, Caracelli, \& Graham, 1989). No formal weighting or priority of quantitative or qualitative data was defined prior to the research since weighting is problematic and the outcomes of most large research projects are rarely predictable (Guest, 2013).

Along with pragmatism, this study employs a transformative-emancipatory perspective with a particular focus on stakeholder participation, critical reflection, questioning of assumptions, multiple contexts, and recognition of divergent views as guiding research principles. Overall, the research process was characterized by close collaboration and synergism between the research team and the consortium partners with multiple points of input and feedback. All key results were either available continuously (web analytics results) or returned frequently (interviews and focus groups results) to all consortium partners as a means of checking their validity, expansion, or questioning.

\subsection{Quantitative Methods}

Two quantitative data collection methods were used in the study: web analytics (Google Analytics) and survey via online questionnaire (Google Form). Web analytics generated purely quantitative data whereas the surveys generated quantitative and qualitative data. In addition, 20 quantitative KPIs were used as complementary data source. All quantitative data were analyzed with descriptive statistics.

Web analytics (web traffic statistics) were used from June 23, 2011 until June 30, 2011 on all 13 MyUniversity portals and the EU super-portal to systematically measure, collect, and analyze visitor demographics and behavior. The analysis focused on nine variables: visits, unique visitors, average visit duration, bounce rate, engagement, interest, geographic origin of visits, and visitors' browser and mobile profile.

The first user survey was conducted in December 2011. Invitations to an online questionnaire were sent out to all registered users of six MyUniversity portals: URJC, UL, UNIAG, PU, UNWE, and $\mathrm{VU}$. Seven portals were not operational at the time and were therefore excluded from the survey. The questionnaire included 20 multiple-choice and open-ended questions, generating quantitative and qualitative data respectively. All translations into local languages were done by the trial managers themselves. 
Informed by the results of the first user survey, a second user survey was conducted in June 2013, covering all 13 MyUniversity portals. The questionnaire included 14 multiple-choice and open-ended questions. All translations into local languages were done, as previously, by the trial managers.

A third online survey of the trial managers was conducted at the end of May-beginning of June 2013. The questionnaire covered 33 questions and employed a three-layered model integrating a project perspective, a sociotechnical perspective, and a democratic perspective. The majority of the questions combined a multiple-choice and an open-ended format. First, the respondents were asked to respond to a statement by giving their opinion on a seven-point Likert item. Three formats were specified for this purpose:

- strongly agree, agree, somewhat agree, neither agree nor disagree, somewhat disagree, disagree, strongly disagree;

- completely satisfied, mostly satisfied, somewhat satisfied, neither satisfied nor dissatisfied, somewhat dissatisfied, mostly dissatisfied, completely dissatisfied;

- extremely important, very important, important, moderately important, of little importance, unimportant.

Then, the respondents were asked to explain their opinion in a follow-up open-ended question. This combination of a multiple-choice and an open-ended question frequently revealed the occurrence of acquiescence bias (a tendency to agree with a statement despite doubts). Typically, the respondents tended to agree with the statement in the initial multiple-choice question, but expressed doubt in the subsequent open-ended question. Therefore, it was acknowledged that the quantitative results of the trial manager questionnaire were positively biased. The questionnaire was anonymous to ensure confidentiality.

To indicate the performance of MyUniversity at project and trial levels, KPIs were used as a complementary data source. The KPIs focused on measurable factors related to the use of the MyUniversity portals. A complete list of all KPIs is available in Section 3.

\subsection{Qualitative Methods}

Complementary to the quantitative methods, five qualitative data collection methods were used in the study: focus groups, participant observation, interviews, document studies, and usability evaluations. All qualitative data were managed, partially transcribed, coded and analyzed with mixed-method data analysis software (NVivo Server 10) which enabled real-time collaboration among the researchers.

The first focus group was conducted with the Swedish National Bologna Expert Group on May 4, 2011 in Stockholm, Sweden. The purpose was to discuss MyUniversity in relation to the Swedish higher education sector. The focus group discussion was recorded by written field notes.

A full-day seminar arranged by the Swedish National Bologna Expert Group and the International Program Office for Education and Training (a Swedish government agency) was attended on May 4, 2011 by one of the researchers. The theme of the seminar was the openness of higher education institutions. Approximately 200 people attended the seminar including rectors, deans, teachers, students, government officials, and industry representatives. Written field notes were taken during the day.

In-depth interviews were conducted with two Bologna Process professionals at Stockholm University on June 27 and 28, 2012 respectively. The topic of discussion was MyUniversity in the context of the Bologna Process at Stockholm University and internationally. The interviews lasted approximately two hours and were recorded with digital voice recorders and written field notes.

A second focus group was conducted with 24 consortium members on September 28, 2012 during the fourth project meeting in Barcelona, Spain. The purpose of the meeting was to decide on relevant topics for the MyUniversity EU super-portal. For this purpose, an online e-voting service 
(VotelT.com) was used. The process and outcome of the focus group was recorded in the e-voting tool supported by written field notes.

Semi-structured interviews were conducted with 20 consortium members on February 11, 2013 during the fifth project meeting in Sofia, Bulgaria. The interviews were conducted by the consortium members themselves using a participatory approach in which each person acted as both interviewer and informant. The two roles were rotated according to a schedule. All interviews were aided by an interview guide. In total, 15 hours of audio were recorded digitally.

A third focus group was conducted with 13 consortium members on July 3 and 4, 2013 during the sixth project meeting in Stockholm, Sweden. The purpose of the focus group was to present preliminary findings, receive feedback, and gather complementary information. Approximately 10 hours of audio were recorded during the two days.

A literature and project documentation review was conducted between February and July 2013, covering 800 items in the literature review and approximately 1,000 pages of project documentation including deliverables, reports, meeting minutes, and presentations available in the project repository and through personal correspondence. The literature was analyzed together with other available data for a richer understanding of theories and concepts.

Additionally, usability and technical evaluations of the MyUniversity platform were conducted on several occasions in 2012 by a research team at the Department of Computer and Systems Sciences at Stockholm University.

\subsection{Integration}

Integration of quantitative and qualitative components occurred during data collection, data analysis, and interpretation stages of the research process. During data collection, all three surveys collected and integrated quantitative and qualitative data in a single questionnaire. The third survey made use of a systematic integration of quantitative and qualitative perspectives. During data analysis and interpretation, automatic queries and manual searches for themes were conducted by observing the frequency of the occurrence of incidents, words, or phrases denoting a particular phenomenon or theme (Bryman, 2012). This process of converting qualitative data into frequencies elevated some themes over others and enabled comparison with quantitative data.

A visual model of the research process is presented in Figure 1, explaining when and how various quantitative and qualitative data collection methods were used and integrated. The sequence in which the methods were used is indicated by a timeline. The backdrop curve of the visual model displays overall visits to MyUniversity to provide additional context. 


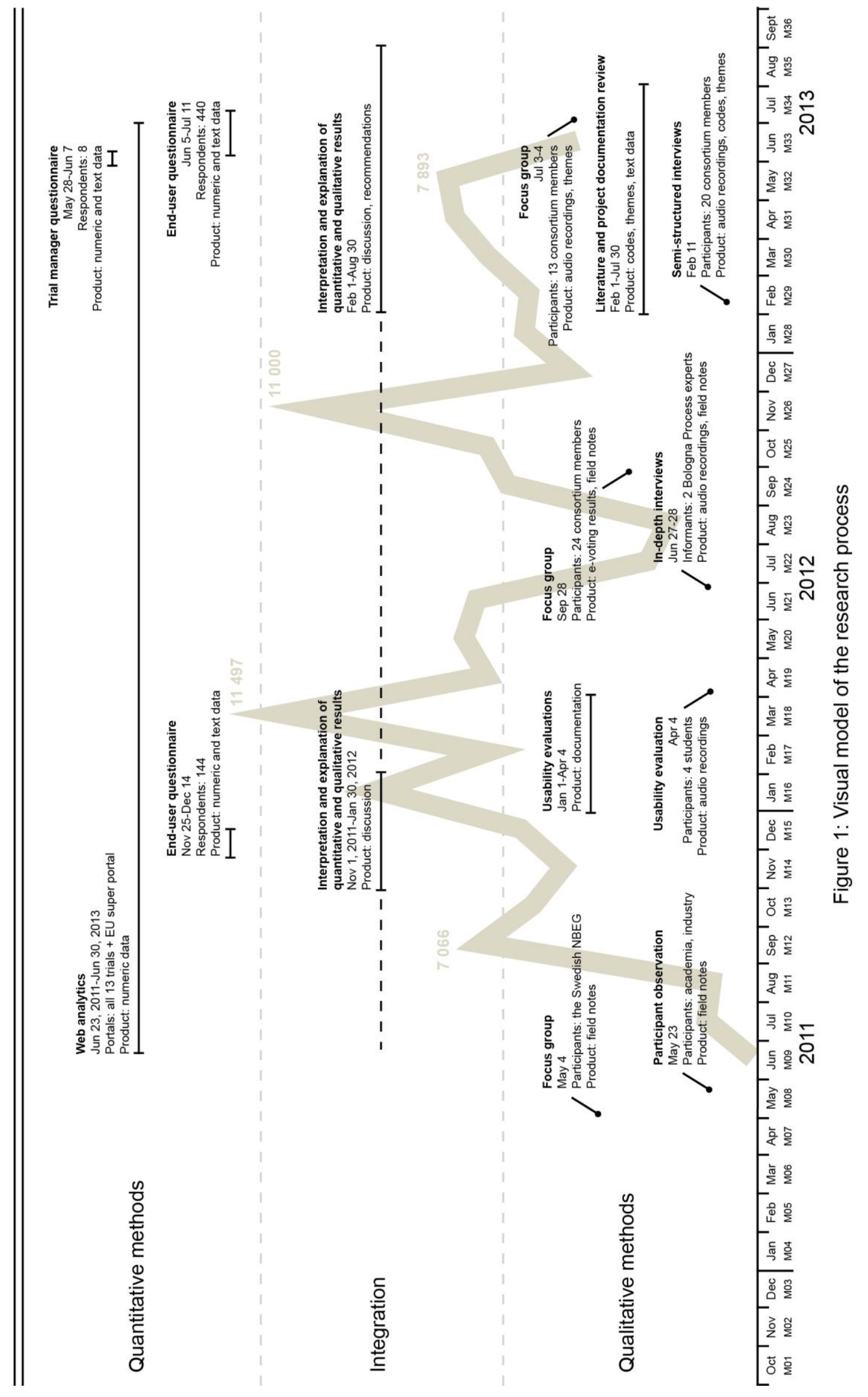




\section{Results}

This section presents the results thematically for a holistic understanding of the MyUniversity trials. It concludes with a brief SWOT analysis.

\subsection{Project Design}

In a recent study on the development of e-participation in the EU, the authors highlighted the need for better project design (Millard et al., 2009). Ironically, one of its main lessons was: "A lot has been learned but is seldom applied, so there is too much re-learning of the same lessons and too much repetition of the same mistakes" (p. 18). This lesson applies largely to the MyUniversity project. Its weak theoretical underpinning, poor methodology, and neglect of e-participation good practices contributed strongly to its poor performance and outcome. First, the project focused too much on technology and tools while neglecting other more relevant, contextual factors. Second, the lack of methodological awareness resulted in faulty interventions and inefficient project management. Third, a failure to learn from good practices resulted in inefficient initiatives, low usability, and low participation. These primary weaknesses of MyUniversity resulted in the barriers and drawbacks outlined in this article.

The trial managers found it difficult to understand and follow the proposed e-participation guidelines, including how to set up and manage initiatives. The project methodology was based on three textbook models: an e-participation program cycle model (including these steps: programming, planning, design, implementation, and evaluation), a typical citizen engagement ladder model (including these rungs: information, consultation, collaboration, and empowerment), and a policy cycle model (including these elements: agenda setting, policy analysis, policy formulation, policy implementation, and policy monitoring). It is not surprising the trial managers found it difficult to follow these supposedly rational models since they are biased. As a result, several trial managers abandoned the official project methodology for more practical approaches better suited to their particular contexts.

An important aspect of the project design was the key performance indicator (KPI) methodology. In total, 13 of 20 project objectives were met (bold) in the final period of the project; see Table 1.

Table 1: KPI results of the final period of the project

\begin{tabular}{|l|r|r|}
\hline Key performance indicator & Objective & Performance \\
\hline 1. Number of universities participating in the project & 18 & $\mathbf{2 2}$ \\
\hline 2. Number of active portals & 14 & 13 \\
\hline 3. Mean number of initiatives per active portals & 10 & $\mathbf{1 1}$ \\
\hline 4. Mean number of portal visits & 2,000 & $\mathbf{1 1 , 6 9 7}$ \\
\hline 5. Mean number of registered users & $4 \%$ & $\mathbf{6 \%}$ \\
\hline 6A. Mean number of forum replies per initiative & 50 & 40 \\
\hline 6B. Mean number of e-consultation replies per initiative & 50 & 31 \\
\hline 6C. Mean number of poll votes per initiative & 50 & $\mathbf{1 8 9}$ \\
\hline 7. Number of cross-border initiatives & 5 & $\mathbf{1 2}$ \\
\hline 8. Mean number of universities per cross-border initiative & 4 & $\mathbf{5}$ \\
\hline 9A. Mean number of forum replies per cross-border initiative & 50 & 32 \\
\hline 9B. Mean number of e-consultation replies per cross-border initiative & 50 & 45 \\
\hline
\end{tabular}




\begin{tabular}{|l|r|r|}
\hline 10. Mean number of initiatives related to the Bologna Process & 6 & 5 \\
\hline 11A. Mean number of reports sent to decision-makers & 8 & $\mathbf{1 4}$ \\
\hline 11B. Mean number of replies from decision-makers & $15 \%$ & $\mathbf{7 4 \%}$ \\
\hline 12. Mean number of reports sent to National Bologna Expert Groups & 5 & 2 \\
\hline 13. Impact on university decision-making & 4 & 4 \\
\hline 14. Impact on National Bologna Expert Groups & 4 & 4 \\
\hline 15. Number of references to the project in media & 18 & 20 \\
\hline 16. Number of third-party events & 6 & $\mathbf{2 9}$ \\
\hline
\end{tabular}

What is interesting about the KPIs is not whether the project objectives were met or not but the rationale behind them and their key role as tools for project management and planning. At first glance, the KPIs make sense since they provide figures on a number of important variables for measuring project performance. However, they only include variables that can be measured or expressed quantitatively, whereas we know that many aspects that are important for understanding complex social phenomena cannot easily or justifiably be translated into numbers. This narrow focus excluded important qualitative aspects that would have enabled a deeper understanding of the MyUniversity trials. Furthermore, most KPI objectives were set arbitrarily as the e-participation field lacks an understanding of what constitutes a good or a bad result. The five KPIs which in the end were given an objective of 50 contributions (KPI 6A, 6B, 6C, 9A, and 9B) were initially given an objective of 200 contributions. These figures were subsequently reduced by half twice as a result of negotiations between members of the project consortium. The objectives of KPI 4 and 5 were equally arbitrarily set. In the end, the KPIs designed to be an effective tool for project management and evaluation were in effect useless. This fact contributed substantially to the project's poor performance and outcome.

\subsection{Participation}

The web analytics results show that the number of visits (individual sessions) on MyUniversity was generally low; see Figure 2. All fourteen charts display the number of visits on the vertical axis and time on the horizontal axis.
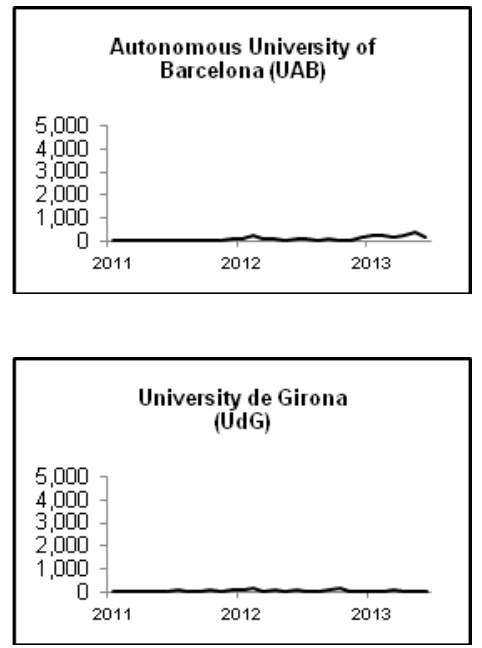
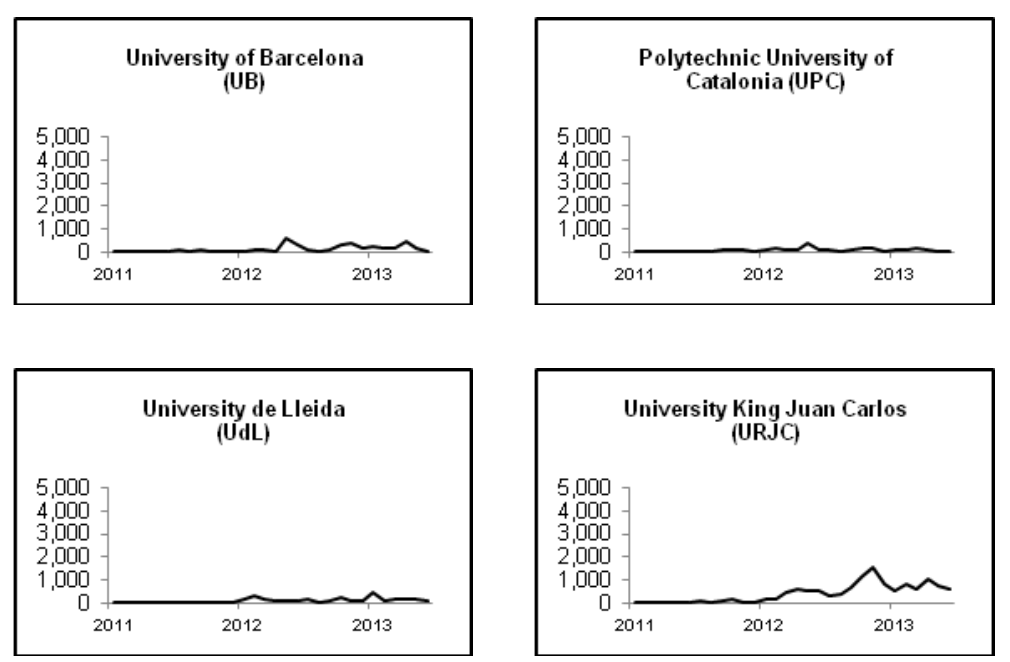

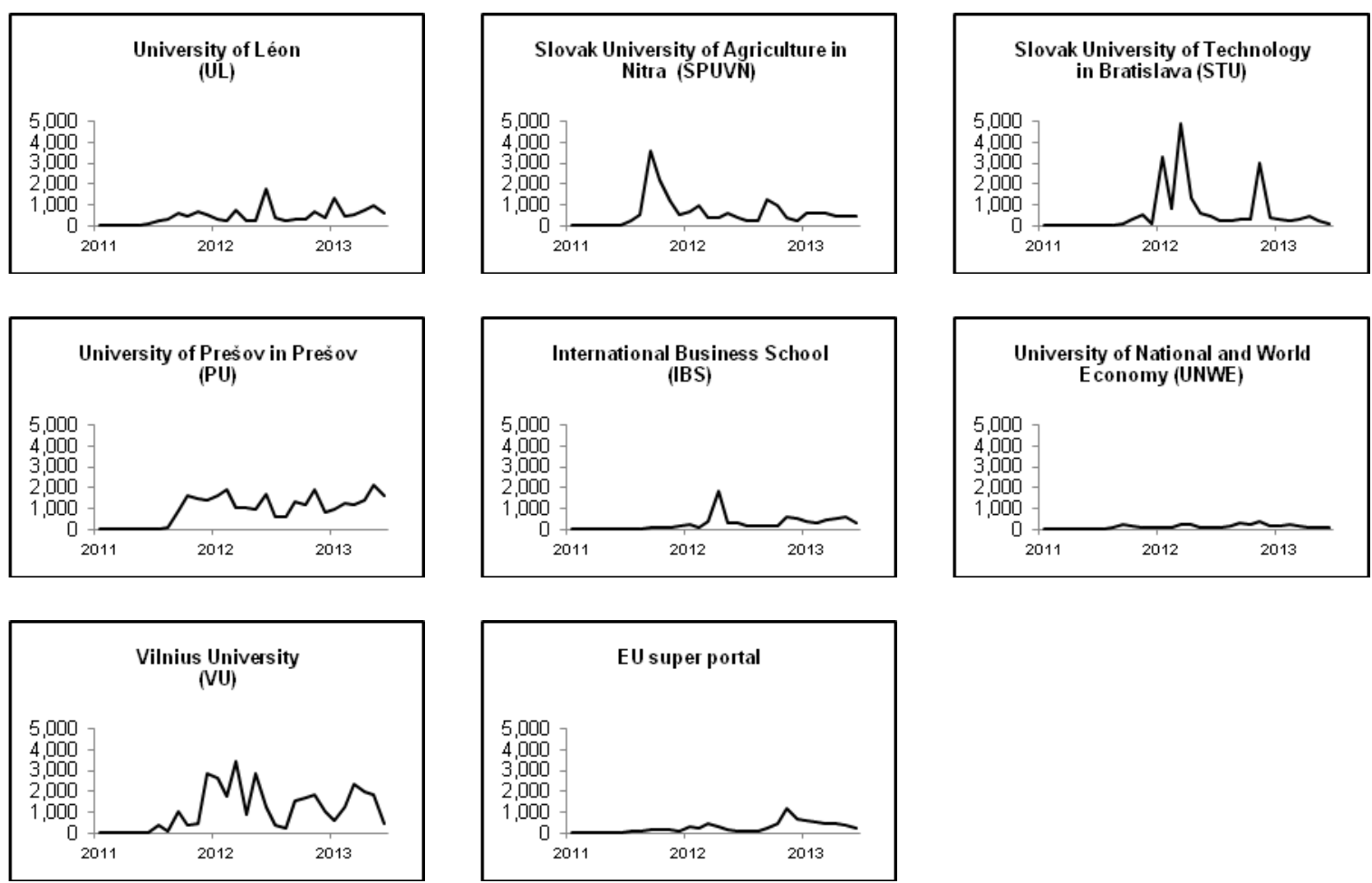

Figure 2: Monthly visits to all MyUniversity portals throughout the project period

As can be seen, visits among the five Catalan trials (UAB, UB, UPC, UdG, and UdL) were particularly low. The two other Spanish trials (URJC and UL) display a somewhat greater number of visits to their MyUniversity portals. Visits to the three Slovakian trials (SPUVN, STU, and PU) were comparatively high. The graphs of SPUVN and STU display a few sharp peaks suggesting short-lived but successful initiatives in terms of visits. In comparison, the graph of PU displays frequent but less accentuated peaks suggesting more stable participation. The two Bulgarian trials (IBS and UNWE) had very few visits, similarly to the five Catalan trials. Among all trials, the Lithuanian (VU) had the greatest number of visits. The graph displays a handful of peaks spread out during the project period, suggesting both frequent and relatively successful initiatives in terms of visits. Finally, the number of visits to the MyUniversity EU super-portal was low throughout the whole project, indicating low levels of cross-border participation.

Furthermore, the web analytics results show that visit duration (engagement) and visit frequency (interest) were low overall; see Figure 3. In terms of visit duration, 61 percent of all visits to MyUniversity lasted from one to ten seconds, suggesting low visitor engagement. In terms of visit frequency, 63 percent visited MyUniversity only once. The horizontal axis in both charts displays total visits expressed as a percentage.
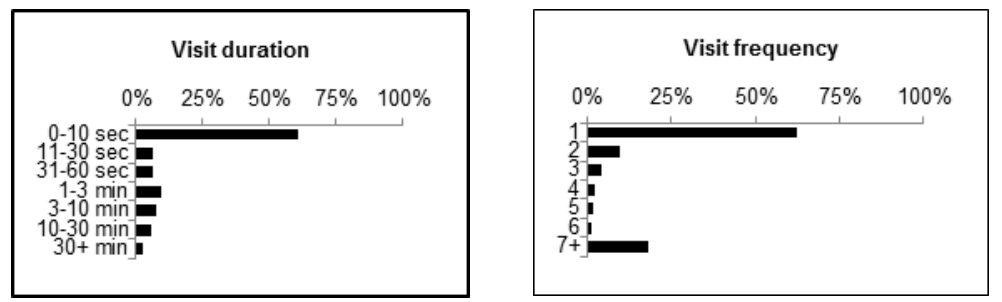

Figure 3: MyUniversity visit duration and visit frequency 
The response rates of both user surveys were low. In total, 143 of 1,001 registered users responded to the first user survey, which constitutes a response rate of 14 percent. In the second user survey, 440 of 5,540 registered users responded, which constitutes a response rate of eight percent. Among the five Catalan trials, the response rate of the second user survey was particularly low. Because of the low response rates of both user surveys, it was acknowledged that the results were biased, i.e., not representative of the target population, and must be interpreted carefully. Nevertheless, the survey results were useful in comparison with results obtained through other methods, according to the mixed-methods approach outlined above.

The user survey results show that the typical MyUniversity visitor was a female student between 21 and 30 years old. She found out about MyUniversity through friends or colleagues, a poster/leaflet on campus, or through a hyperlink from another website, typically the university website. Her purpose in visiting MyUniversity was mixed. Commonly, visitors came to the website to find out more about the platform and out of curiosity. Some visitors wanted to be part of higher education discussions and decision-making. Others visited MyUniversity in order to win a prize (a trip to Thailand). For some students, it was mandatory to register on MyUniversity in order to receive course credits. This result illustrated how difficult it was for the trial managers to attract students to the platform. The typical survey respondent intended to visit MyUniversity again, and replied that $\mathrm{s} /$ he would recommend MyUniversity to a friend or a colleague.

The interview results suggest that students, in particular first-year students, were easier to engage than other stakeholder groups. It was more difficult to engage teachers, researchers, administrative staffs, rectors, deans, Bologna Process experts, alumni, government officials, businesses, and non-governmental organizations. One trial manager commented:

"There was no space in the project to work parallel with two target groups - students and teachers - in order to invite them to participate. Each requires a different approach."

First-year students were thought to be more willing to engage in various activities at their university and more open to discussion and debate than other groups. It was also assumed they were better adapted to modern ICT and social media.

\subsection{Functionality and Usability}

Good practice recommendations suggest that online participation must be engaging to ensure maximum participation since abstract concepts such as politics and democracy are not interesting enough to most people. One way of working towards an attractive and engaging online experience is to design an appealing and easy-to-use interface. This includes graphic design, layout, navigation, customizability, adherence to web standards, etc. All of these aspects of MyUniversity were poor. The usability evaluations identified over 50 problems, including violations of the principles of aesthetic and minimalist design, consistency and standards, and visibility of system status. Furthermore, MyUniversity's core content management system was questionable in terms of security and sustainability. Trial managers and students also repeatedly stressed that the tools on MyUniversity were non-user-friendly, too complex, or unappealing.

The proprietary voting tool Pnyx exhibited several drawbacks; in particular, installation and administration of the software was thought to be too complicated. A PC using the Windows operating system required the installation of an older version of Java and a cryptography extension. A Mac required a downgrade of the entire operating system to an older version. Obviously, these requirements were too demanding for most administrators, a fact which resulted in the tool's limited uptake among the trials.

Surprisingly, the typical survey respondent thought MyUniversity was relevant, user-friendly, easy to learn, appealing, and satisfactory overall. However, the typical respondent recognized the need for improving MyUniversity's design and layout. The typical respondent considered MyUniversity a good platform for discussion and debate, but only somewhat agreed that it was good for decision-making. Among all the MyUniversity tools, the typical respondent was most 
satisfied with the discussion forum and least satisfied with the petition tool and the letters tool. The petition tool enabled users to gather electronic signatures and address them to government officials, and the purpose of the letters tool was to allow citizens to send letters to officials. Both tools were legacies of the Gov2DemoSS platform and obviously made less sense in a higher education context. Indeed, one trial manager reported:

"Many tools like petition, calendar, newsletter, etc. were not really viewed by the users."

MyUniversity had one tool that all agreed was user-friendly - the quick poll. It was simple to manage and simple to use. It did not require any registration or identification, a fact which probably contributed to its relative popularity among the trials. However, the quick poll was flawed as it did not control the eligibility of voters and how many times a voter could vote. Consequently, the quick poll was inappropriate as a tool for decision-making.

Leveraging the success of popular social media for e-participation purposes proved to be more difficult than anticipated. MyUniversity was repeatedly compared with Facebook and Twitter in terms of functionality and ease of use. One trial manager said:

"MyUniversity needs a new design which is more interactive and closer to tools like Facebook and Twitter."

The project tried to attract new users to MyUniversity by leveraging the popularity of Facebook and Twitter by advertising its content on them. However, the advertising efforts failed, having little, or in some cases even negative, effect on participation. One trial manager reported that many topics that were simultaneously posted on MyUniversity and Facebook were quickly lost to the popular social networking site. Instead of attracting new users to MyUniversity, the Facebook integration made it easier for existing users to leave the platform and take their discussions with them. In the case of Twitter, one trial manager commented:

"Twitter is not popular enough in Bulgaria."

The trial manager interviews indicate that academic staff members are tired of online portals and tools that involve a cumbersome registration process and a steep learning curve. MyUniversity would have probably benefited from having been integrated within the existing university ICT system, for example, the university website, instead of being a separate platform distant from the organizational context.

Overall, MyUniversity's poor functionality and low usability became a barrier to engagement and participation.

\subsection{Impact on Decision-making}

Impact on decision-making was low in all trials, in particular among cross-border initiatives on the EU super-portal. The lowest participation rates were achieved in initiatives related to the Bologna Process, and conversely the highest participation rates were achieved in initiatives that addressed local issues. One trial manager commented:

"Each university was mostly operating separately, involved in their problems. The super-portal in my opinion was not attractive, not interesting for most people, therefore we did not learn much from each other and did not compare ...maybe we did not have the time or conditions for that."

Initiatives related to the Bologna Process were largely considered irrelevant by the MyUniversity users, which made it difficult for the trial managers to generate engaging topics. One trial manager commented:

"The Bologna Process is a complicated, quite boring topic, [...], so it was very difficult to find connected themes." 
It was also challenging for the trial managers to engage the National Bologna Expert Groups, which in turn made it difficult for them to raise MyUniversity to a higher policy level. Several trial managers questioned the idea that a pilot project such as MyUniversity could influence the Bologna Process. One trial manager said:

"It is a Utopia that it [the Bologna Process] could be influenced via platform contributions."

Surprisingly, the survey results indicated that the typical user thought MyUniversity was a good platform for Bologna Process discussions, yet s/he was never involved in a Bologna Process discussion on the platform. These conflicting results suggest that the average respondent had a poor understanding of the Bologna Process and the purpose of MyUniversity.

During in-depth interviews, several informants underlined the social complexity of higher education and the Bologna Process. In particular, they stressed that the work program of the Bologna Process may seem straightforward on the surface with a number of distinct themes such as quality assurance or employability. However, in reality, these themes are fluid and embedded in daily work practices. Most of what could potentially be labeled "Bologna Process" is distributed among faculties, departments, and working groups as part of administration, teaching, and research. It is therefore a mistake to believe that university decision-making or the Bologna Process can be influenced by an e-participation platform such as MyUniversity, especially in view of the limitations of the ICT used by universities today. Additionally, contrary to the project's basic assumption, two informants stressed that the Bologna Process was generally considered a success. Similarly, one trial manager commented:

"In Bulgaria, the Ministry accepts that Bologna issues are already resolved and functioning."

Several trials were relatively successful in engaging their students by focusing on local needs. For example, the most successful initiative at Vilnius University concerned a proposal for change regarding foreign language teaching. It was a popular topic among the students and received over 1,700 quick poll votes on their MyUniversity website. Other successful local initiatives included the "new study room or library" initiative at Slovak University of Agriculture in Nitra, the "quality of the canteens" initiative at Slovak University of Technology in Bratislava, and the "new student code of conduct" initiative at the University of Prešov in Prešov. One trial manager commented:

"The students are generally not involved in university management, except for their issues, but we have used the project mainly for improved management of the teaching process, which is the most important process at any university."

Three common success factors in the above-mentioned initiatives were a focus on local needs, support from the university management, and a combination of online and offline activities.

\subsection{Privacy and Trust}

The issue of privacy and trust proved to be more difficult than anticipated among all trials. Various challenges were debated within the consortium on a number of occasions, including arguments both in favor and against a real-name policy. The results of the trial manager questionnaire exemplify diverse views among the trial managers on the topic:

"Some of our community members do not like to be identified, and we usually agree, if we want to encourage discussion."

"We think it is very important [not to be identified]... many of our users participated only on this condition."

"It seems that it was important only for some of the participants [not to be identified], whereas others did not have a problem with it."

"If you want to change something in the university, you need to identify who you are." 
The common approach among the trials was to require the users to be registered on MyUniversity in order to use the discussion forum and Pnyx, but not the quick poll. The Spanish trials, particularly the five Catalan universities, chose a more restrictive approach in which the users were required to identify themselves via single sign-on technology before participating in the platform. However, the enforced identification procedure was highly unpopular among the Catalan students and their willingness to identify themselves was low. Consequently, visits to the Catalan MyUniversity portals suffered correspondingly. One trial manager commented:

"Users have organized themselves using open tools such as blogs, public and private Facebook pages, Twitter, etc. Thus, MyUniversity tools have been considered an institutional instrument that has not represented an advantage to the users. On the other hand, the university management values the security and reliability of the information provided using these tools, although they admit they have not succeeded in attracting users to the portal."

The Slovakian (SPUVN, STU, and PU) and Bulgarian (UNWE and IBS) trials were less restrictive with regard to identification, a fact which probably contributed to greater numbers of visits on their MyUniversity portals. However, several Eastern European trial managers reported that their countries lacked democratic culture, which made their students reluctant to take part in debates and express their personal opinions. One trial manager commented:

"Even if you could register with nicknames or whatever, still people feel suspicious. [...] They still think that somehow they will be revealed, although we have repeated several times it is safe and that we are not going to do that."

\subsection{Institutional Resistance}

Institutional resistance and low levels of management commitment raised organizational barriers that had a negative effect on all trials. This problem prompted some trial managers to search for new opportunities. For example, the trial manager at University King Juan Carlos in Spain who felt isolated at his institution decided to take MyUniversity abroad to South America. This change of strategy turned out to be rather successful; in fact, the trial's highest number of visits came from Mexico (2,738 visits), not Spain (1,491 visits).

Interview results suggest changing people's attitudes and behavior is difficult and takes time. Not all decision-makers are willing to open up the debate and make decisions based on a single eparticipation pilot. The real benefit of these trials has been decision-makers becoming aware of students' lack of trust towards them and their low expectations of e-participation. Furthermore, the trial managers learned that the goal of MyUniversity was not only to test new ICT but also to analyze existing decision-making practices and provide opportunities for change.

\subsection{Motivational Factors}

With regard to the problem of institutional resistance and participation in general, issues of motivation and incentive arise. Clearly, future e-participation projects in higher education need to provide stronger incentives for participation. The standard slogans "Participate!" "Share your opinion!" or "Influence the decision-making process!" are simply not encouraging enough. What future e-participation projects in higher education need to answer is the question "What's in it for X?" for all key stakeholder groups including students, teachers, and decision-makers. Concrete benefits in the form of course credits, vouchers, or recognition could perhaps be used effectively depending on the particular stakeholder group and context. 


\subsection{The Political, Economic, and Socio-cultural Context}

The European financial crisis and the political instability that followed in its wake were seen as a barrier to participation for all trials. One trial manager commented:

"It is difficult to persuade people to behave in a democratic way while they cannot see this type of behavior on the part of the government."

In Catalonia, the students expected debatable topics on current events related to the economic crisis and financial cuts. However, the topic was considered too controversial by the university management, who banned it from their MyUniversity portals. As a result, the five Catalan trials were unable to provide a meaningful e-participation platform to their university communities.

These results suggest there are important political, economic, and sociocultural differences among the trials that vary from country to country and from institution to institution, including political structure, democratic tradition, and trust in public institutions. These factors need to be studied further by acknowledging the differences that exist across Europe.

\subsection{Language Barriers}

Language barriers and low English proficiency among the university populations hindered crossborder participation on the MyUniversity EU super-portal. This problem was partly foreseen, and an automatic translation module based on Google Translate was developed to handle it. However, the translation module was inadequate and, therefore, rarely used. One trial manager commented:

"Google Translate does not work when you translate [their language], it is nonsense?"

A language barrier was also evident within the multi-country project consortium itself, inhibiting effective communication and cooperation. English was the working language of the project, but only one consortium member was a native English speaker. Furthermore, translations of press releases, questionnaires, and other documents required more time and resources than anticipated.

\subsection{Moderation and Framing}

Some trial managers expressed the need for moderation and framing of debates in order to promote trust, reinforce ethical standards, and generally raise the quality of the online discussions. For example, the forum moderator at University of National and World Economy never had to remove a contribution because of inappropriate content, but noticed that some users in the discussion forum censored themselves by deleting their own contributions as if they were afraid of sharing their opinion. The clear presence of a moderator and a stronger democratic framework may have helped in this case. Nevertheless, moderation never really became an issue in any of the trials. One possible explanation is that participation in the discussion forums was generally low and no heated debates ever took place. The censoring of controversial topics in MyUniversity probably contributed to this outcome.

\subsection{SWOT Analysis}

Based on two SWOT analyses performed during the course of the project (the first was part of the trial manager survey, the second was performed by the project consortium during the sixth project meeting), a final SWOT analysis was done to provide a condensed presentation of MyUniversity's strengths, weakness, opportunities and threats; see Table 2. Analysis of MyUniversity from a SWOT perspective means a number of critical issues in terms of evaluating the platform's sustainability can be identified. 
Table 2: SWOT analysis of MyUniversity

\begin{tabular}{|c|c|}
\hline Strengths & Weaknesses \\
\hline $\begin{array}{l}\text { - Influenced decisions locally; } \\
\text { - An institutional space for problem- } \\
\text { solving; } \\
\text { - Increased collaboration among } \\
\text { universities; } \\
\text { - Provided a variety of ICT tools; } \\
\text { - Open source architecture; } \\
\text { - Provides a foundation for future e- } \\
\text { participation practice and research; }\end{array}$ & $\begin{array}{l}\text { - Poor project design; } \\
\text { - Too much focus on technology; } \\
\text { - Not embedded in the workplace } \\
\text { context; } \\
\text { - Low interest in the Bologna Process; } \\
\text { - Too complex or non-user-friendly } \\
\text { tools; } \\
\text { - Unsuccessful integration with social } \\
\text { - } \text { media; } \\
\text { - Low management commitment; } \\
\text { - Questionable sustainability; }\end{array}$ \\
\hline Opportunities & Threats \\
\hline $\begin{array}{l}\text { - Could be extended with more } \\
\text { advanced decision support features; } \\
\text { - Bottom-up approaches may } \\
\text { accelerate the Bologna Process; } \\
\text { - May foster democratic values and a } \\
\text { culture of participation; }\end{array}$ & $\begin{array}{l}\text { - Rapid changes in technology; } \\
\text { - Alternative technologies and tools; } \\
\text { - Bologna Process is an abstract topic; } \\
\text { - Different democratic traditions; } \\
\text { - Language barriers limit collaboration; } \\
\text { - Academia is resistant to change; } \\
\text { - Financial crisis and political instability; }\end{array}$ \\
\hline
\end{tabular}

\section{Discussion}

By using a comprehensive, mixed-methods research design, this study provides insight into ten themes relating to the design, implementation, and outcome of the MyUniversity EU project. Most results and conclusions are wide-ranging, covering all trials, whereas some are more specific. Some consortium partners may find some of the conclusions provocative, depending on their particular role and stake in the project. However, the purpose is not to single out an individual or a consortium partner for negative treatment or blame, but to provide a foundation for a constructive discussion on the future of e-participation.

MyUniversity was promoted as "innovative" and "cutting edge"; however, this study paints a less flattering picture. In the end, MyUniversity lacked the technology, the engagement, and trust it needed in order to be successful. The students, the most important stakeholder group, were generally uninterested or skeptical towards MyUniversity, in particular when they had to identify themselves before participating on the platform. Despite poor performance and outcomes, most trial managers found the MyUniversity pilot project a worthwhile experience. If nothing else, this is a positive result and provides a small step forward. However, the greater part of the study results makes MyUniversity's sustainability questionable. Comprehensive re-design in terms of technology 
and methodology based upon current research and good practices is needed to make the platform functional, engaging, and secure.

The results of this study confirm previous research that underlines the unsatisfactory development of the e-participation field. A number of challenges and barriers described in the literature can be identified in the study, including technological determinism, institutional resistance, language barriers, privacy and trust issues, low usability, faulty or misaligned interventions, and the lack of bottom-up approaches. Additional lessons learned and future recommendations include:

- need for better project design;

- embrace agile development methods;

- focus on solving real needs at the outset;

- combine online and offline activities;

- have realistic goals and ambitions; institutions are resistant to change;

- technology and tools must be appealing and easy to use;

- explore and leverage popular social networking services;

- high-level support is important;

- find a balance between power-sharing and problem-solving;

- embed the project in daily work practices;

- evaluate and conduct rigorous research about what works and why.

Above all, the study accords with previous research which has highlighted the need to replace the current e-government approach to civic engagement with a new citizen-centric model. Many EU-sponsored e-participation projects from the early 2000s were promoted as bottom-up and Web 2.0 but were, in fact, built on a top-down, supply-centric approach that has proven to be inadequate for engaging citizens time after time. Instead, e-participation practitioners need to learn how to leverage the spontaneous formation of new grass-roots movements and Internet activism which have lately mushroomed all over the world; the financial crisis protests, the Arab Spring, and Occupy Wall Street are three prominent examples. Indeed, a new agenda for e-participation research was outlined over five years ago:

"Web 2.0 environments, such as YouTube, Wikipedia, Facebook, citizen blogging, etc., constitute now the new frontier of citizen interaction in the online world. We need to shift our focus from the top-down, institution-initiated e-participation platforms to the bottom-up, citizen-initiated ones which are playing an increasingly relevant role in shaping the way citizens interact with decision-makers and the institutions." (Medaglia et al., 2008, p. 68)

Practitioners in the field of e-participation need to stop repeating the same mistakes and start applying what has been learned. Only then can the field move forward.

\section{References}

Aicholzer, G., Allhutter, D., Freschi, A. C., Lippa, B., Macintosh, A., Moss, G., \& Welstholm, H. (2008). eParticipation evaluation and impact (D13.3 DEMO-net booklet). Institut für Informationsmanagement Bremen GmbH, University of Leeds.

Bryman, A. (2006). Integrating quantitative and qualitative research: how is it done? Qualitative Research, 6(1), 97-113. doi:10.1177/1468794106058877

Bryman, A. (2012). Social research methods. Oxford: Oxford University Press.

Chadwick, A. (2011). Explaining the failure of an online citizen engagement initiative: The role of internal institutional variables. Journal of Information Technology \& Politics, 8(1), 21-40. doi:10.1080/19331681.2010.507999

Chrissafis, T., \& Rohen, M. (2010). European eParticipation developments: From ad hoc experiences towards mass scale engagement. JeDEM - eJournal of eDemocracy and Open Government, 2(2), 89-98.

Freschi, A., Medaglia, R., \& Nørbjerg, J. (2009). A tale of six countries: eParticipation research from an administration and political perspective. In A. Macintosh \& E. Tambouris (Eds.), Electronic Participation (Vol. 5694, pp. 36-45). Springer Berlin Heidelberg. 
Greene, J. C., Caracelli, V. J., \& Graham, W. F. (1989). Toward a conceptual framework for mixed-method evaluation designs. Educational Evaluation and Policy Analysis, 11(3), 255-274. doi:10.2307/1163620

Grönlund, A. (2009). ICT is not participation is not democracy - eParticipation development models revisited. In A. Macintosh \& E. Tambouris (Eds.), Electronic Participation (Vol. 5694, pp. 12-23). Springer Berlin Heidelberg.

Guest, G. (2013). Describing mixed methods research: An alternative to typologies. Journal of Mixed Methods Research, 7(2), 141-151. doi:10.1177/1558689812461179

Koussouris, S., Charalabidis, Y., \& Askounis, D. (2011). A review of the European Union eParticipation action pilot projects. Transforming Government: People, Process and Policy, 5(1), 8-19. doi:10.1108/17506161111114617

Macintosh, A. (2004). Characterizing e-participation in policy-making. In Proceedings of the 37th Annual Hawaii International Conference on System Sciences, 2004. IEEE. doi:10.1109/HICSS.2004.1265300

Macintosh, A. (2008). E-democracy and e-participation research in Europe. In H. Chen, L. Brandt, V. Gregg, R. Traunmüller, S. Dawes, E. Hovy, ... C. A. Larson (Eds.), Digital Government (Vol. 17, pp. 85-102). Springer US.

Macintosh, A., Coleman, S., \& Schneeberger, A. (2009). eParticipation: The research gaps. In A. Macintosh \& E. Tambouris (Eds.), Electronic Participation (Vol. 5694, pp. 1-11). Springer Berlin Heidelberg.

Macintosh, A., \& Whyte, A. (2006). Evaluating how e-participation changes local democracy. Presented at the eGovernment Workshop '06, Brunel University, West London.

Medaglia, R. (2007). The challenged identity of a field: The state of the art of eParticipation research. Information Polity, 12(3), 169-181.

Medaglia, R. (2011). eParticipation research: A longitudinal overview. In E. Tambouris, A. Macintosh, \& H. de Bruijn (Eds.), Electronic Participation (Vol. 6847, pp. 99-108). Springer Berlin Heidelberg.

Medaglia, R. (2012). eParticipation research: Moving characterization forward (2006-2011). Government Information Quarterly, 29(3), 346-360. doi:10.1016/j.giq.2012.02.010

Medaglia, R., Nørbjerg, J., Secher, C., Vedel, T., Freschi, A. C., Raffini, L., ... Saurwein, F. (2008). eParticipation in the institutional domain: A review of research. CBS, University of Bergamo.

Millard, J., Nielsen, M. M., Warren, R., Smith, S., Macintosh, A., Tarabanis, K., ... Parisopoulos, K. (2009). European eParticipation summary report. Brussels: European Commission.

Oates, B. J. (2006). Researching information systems and computing. London: SAGE.

Panopoulou, E., Tambouris, E., \& Tarabanis, K. (2009). eParticipation initiatives: How is Europe progressing. European Journal of ePractice, 7, 15-26.

Prieto-Martín, P., de Marcos, L., \& Martínez, J. J. (2012). A critical analysis of EU-funded eParticipation. In Y. Charalabidis \& S. Koussouris (Eds.), Empowering Open and Collaborative Governance (pp. 241-262). Springer Berlin Heidelberg.

Sæbø, Ø., Rose, J., \& Skiftenes Flak, L. (2008). The shape of eParticipation: Characterizing an emerging research area. Government Information Quarterly, 25(3), 400-428. doi:10.1016/j.giq.2007.04.007

Sanford, C., \& Rose, J. (2007). Characterizing eParticipation. International Journal of Information Management, 27(6), 406421. doi:10.1016/j.ijinfomgt.2007.08.002

Smith, S., Macintosh, A., \& Millard, J. (2009). Major factors shaping the development of eParticipation (European eParticipation study and supply of services on the development of eParticipation in the EU, Deliverable 1.1c). European Commission.

Susha, I., \& Grönlund, A. (2012). eParticipation research: Systematizing the field. Government Information Quarterly, 29(3), 373-382. doi:10.1016/j.giq.2011.11.005

Tashakkori, A., \& Teddlie, C. (2003). Handbook of mixed methods in social \& behavioral research. Thousand Oaks, Calif.: SAGE Publications.

\section{About the Authors}

Samuel Bohman is a doctoral student in the Department of Computer and Systems Sciences, Stockholm University, Sweden.

Henrik Hansson is associate professor in the Department of Computer and Systems Sciences, Stockholm University, Sweden.

Pooyeh Mobini is a research assistant in the Department of Computer and Systems Sciences, Stockholm University, Sweden. 